\title{
Tax-Exempt Lobbying: Corporate Philanthropy as a Tool for Political Influence Online Appendix
}

Marianne Bertrand, Matilde Bombardini, Raymond Fisman, and Francesco Trebbi 


\section{A Data Appendix}

\section{A.1 Matching}

We start with the grants by Fortune 500 and S\&P 500 companies as of 2014, a file that has 809,940 observations, covering grants issued between 1998 and 2015. In the initial file we have grants from 332 foundations to 76,321 unique recipients names. The first step is to match by name only when the name in the FoundationSearch file matches perfectly with the name in the BMF. For the remaining unmatched grants, we employed the matching algorithm -matchit- in Stata, which provides similarity scores for strings that may vary because of spelling and word order. We employed the option "token," which reduces computational burden because it splits a string only based on blanks, instead of generating all possible ngrams. Employing matches with a score above 0.85 we match 536,920 observations to the BMF (66.7 percent).

The number of grant-giving foundations with data that we employ is reduced slightly to 324 as a result of this matching process.

\section{A.2 Sample construction}

In this appendix we provide details on how the final sample was constructed. The basic sample is composed of companies in the Fortune 500 or S\&P 500 as of 2014. The unit of analysis is an EIN, which is the code identifying a foundation. There are two important crosswalks that we have constructed. The first one connects the EIN to the client name from the lobbying data, which we use to determine the issues that are of importance to the firm/foundation. We assigned for each EIN one or more client names based on a search performed on the OpenSecrets.org website. There are several cases in which one EIN corresponds to more than one client name in the lobbying records. We keep all the client names that correspond to an EIN and we determine the most lobbied issue (based on total expenditures) for each one of those clients for each congressional

cycle. So for one EIN we potentially end up with several most lobbied issues, but we eliminate duplications (e.g., the top issue lobbied by different divisions of Lockheed Martin is still Defense) and keep the full set of top issues. The second crosswalk is the one between an EIN and a PACID. The PACID is the identifier in the PAC contribution data. If there are multiple PACs per EIN we sum the respective contribution amounts for the relevant period/recipient. If there are two foundations/EINs that correspond to the same PAC, we split the PAC contributions equally in two for the relevant period/recipient.

We take into account redistricting when constructing the panel and assign PACs only when a congressional district exists. Redistricting occurs on the basis of decennial censuses. We allow an additional election cycle of delay (e.g., we only begin using the districts based on the 2010 Census 
in the 113th (2013-14) Congress to account for the fact that states generally take several years to design and implement redistricting plans).

Importantly, because foundations are not active for the entire period (or the data are not fully digitized for the earlier years in the sample), and in order to keep the same sample for both PAC and CSR regressions, we keep only observations in which both contributions are non-missing. This means that we drop some of the years in which PAC data for the firm are available and non-missing, but we do not have data for charitable giving by the corresponding foundation.

\section{B Appendix: Congressional district level aggregation of charitable grants}

This appendix explores the issue of selection of specific grantees by firms with the purpose of providing electoral benefits to a local representative. Specifically, we show how aggregating across grantees within a congressional district and within a congressional cycle alleviates issues of grantee selection and substitution. We also shows through Monte Carlo simulations how regression specifications akin to those employed in Section IV.C of the paper, run at the firm-grantee-congressional cycle level, may suffer from substantial downward bias, as a result of failure to account for issues of grantee selection. The bias is shown to be proportional to the number of grantees in a district, so potentially very large in magnitude.

As in our analysis in Section III.B we employ the following notation. Let firm/foundation be $f$; grantee $g$; time $t$; congressional district $d$. For our main variables, we use the notation $Y_{f g t d}$ for $\ln \left(1+\right.$ Contributions $\left._{f g t d}\right)$ and for a political shock relevant to firm in year $t$ stemming from certain congressional committee appointments $\ln \left(1+\right.$ IssuesCovered $\left._{f d t}\right)$ we use the notation $X_{f d t}$.

\section{B.1 Selection problem and setup}

The econometric problem we present is one in which a firm aims to cater to a politician of relevance to its business and decides to do so through the allocation of charitable grants within that politician's district (e.g. so the she can claim credit for it). We will assume that there is one set of $G$ potential grant recipients located in $d$ and that the firm decides to donate to a subset of $G$ (with abuse of notation we use $G$ for both the set of grantees and its cardinality). In our standard notation, we consider the problem in which a firm $f$ perceives a political shock $X_{f d t}$ and decides to influence the representative from $d$ by donating funds $Y_{f g t d}$ to grantee $g \in G$ located in that congressional district at $t$.

Suppose that $f$ 's funds are limited or that only certain grantees are electorally valuable from the perspective of the political beneficiary (the representative from district $d$ ) at $t$. For the purpose 
of presenting the econometric problem, only one grantee per period is assumed to be chosen as the recipient of grant funds each period. The fact that there is only one grant recipient is not strictly necessary, and all results below will hold if a different (strict) subset of $G$ is selected at each $t$. Let us use the indicator function $I$ ( $f$ chooses to influence the representative from $d$ through $g$ at time $t$ ) to indicate the selection process.

The true underlying econometric specification is therefore:

$$
Y_{f g t d}=\beta X_{f t d} * I(f \text { chooses to go through } g \in G \text { at time } t)+\epsilon_{f g t d}
$$

Note that the econometrician does not observe the choice $I($.$) . (To avoid needless additional$ notation, we do not report the multi-way fixed effects considered in Section III.B.) The econometrician's objective is to estimate the parameter $\beta$.

\section{B.2 Aggregate regression}

As an illustration of how our district level aggregate regressions can address the selection issue presented above, consider the following system of equations:

$$
\begin{aligned}
Y_{f g t d} & =\beta X_{f t d} * I(f \text { chooses to go through } g \text { at time } t)+\epsilon_{f g t d}=\beta X_{f t d}+\epsilon_{f g t d} \\
Y_{f g t^{\prime} d} & =\beta X_{f t^{\prime} d} * I\left(f \text { chooses to go through } g^{\prime} \text { at time } t^{\prime}\right)+\epsilon_{f g t^{\prime} d}=\epsilon_{f g t^{\prime} d} \\
Y_{f g^{\prime} t d} & =\beta X_{f t d} * I(f \text { chooses to go through } g \text { at time } t)+\epsilon_{f g^{\prime} t d}=\epsilon_{f g^{\prime} t d} \\
Y_{f g^{\prime} t^{\prime} d} & =\beta X_{f t^{\prime} d} * I\left(f \text { chooses to go through } g^{\prime} \text { at time } t^{\prime}\right)+\epsilon_{f g^{\prime} t^{\prime} d}=\beta X_{f t^{\prime} d}+\epsilon_{f g^{\prime} t^{\prime} d} \\
Y_{f g^{\prime \prime} t d} & =\beta X_{f t^{\prime} d} * I(f \text { chooses to go through } g \text { at time } t)+\epsilon_{f g^{\prime \prime} t d}=\epsilon_{f g^{\prime \prime} t d} \\
Y_{f g^{\prime \prime} t^{\prime} d} & =\beta X_{f t^{\prime} d} * I\left(f \text { chooses to go through } g^{\prime} \text { at time } t^{\prime}\right)+\epsilon_{f g^{\prime \prime} t^{\prime} d}=\epsilon_{f g^{\prime \prime} t^{\prime} d}
\end{aligned}
$$

Let us indicate with $\beta^{\text {full }}$, the the estimator of the parameter $\beta$ under full knowledge of each selection $I($.$) .$

Now observe that aggregating the information across all potential grantees $k=g, g^{\prime}, g^{\prime \prime}, \ldots$ at time $t$ in $d$ produces an estimating equation of the form:

$$
\sum_{k} Y_{f k t d}=\beta X_{f t d} * \sum_{k} I(f \text { chooses to go through } k \text { at time } t)+\sum_{k} \epsilon_{f k t d}
$$

or, simplifying by noting that $\sum_{k} I(f$ chooses to go through $k$ at time $t)=1$, 


$$
\bar{Y}_{f t d}=\beta X_{f t d}+\bar{\epsilon}_{f t d}
$$

where $\bar{Y}_{f t d}=\sum_{k} Y_{f k t d}$. Let us indicate with $\beta^{a g g}$ the estimator of this regression.

We note that this aggregate approach provides a consistent estimate of $\beta$ (in levels or with fixed effects within congressional district $d$ and over time), because it integrates over the selection by $f$ of which $g$ to employ at every period $t$. In this case, the unobserved choice variables $I(f$ chooses to go through $k$ at time $t)$ drop out of the estimating equation and therefore their omission is immaterial to the consistency of the estimator, that is $p \lim \beta^{a g g}=\beta$.

\section{B.3 Disaggregate regression}

Consider a disaggregated approach to the analysis in which $\beta$ is estimated directly from the system of equations presented in the previous section. This is done without information on which $g$ is selected at each period as the focus of $f$ 's efforts. This implies a regression of the form:

$$
Y_{f g t d}=\beta X_{f t d}+\epsilon_{f g t d}
$$

Let us indicate with $\beta^{\text {dis }}$ the estimator from this regression. This approach averages estimates across periods when $I(f$ chooses to go through $g$ at time $t)=1$ and $I(f$ chooses to go through $g$ at time $t)=0$. For each $g$ this specification leads to inconsistent estimation of $\beta$. In the simplest possible case where $f$ picks one grantee at random in each period, it is evident that the inconsistency of the estimator is determined by $p \lim \beta^{\text {dis }}=\frac{\beta}{G}$. If selection is not random (and thus $I($.$) is correlated with X$ ) the inconsistency will be further amplified by the omission of the selection variable.

\section{B.4 Monte Carlo simulations}

The following Monte Carlo simulations illustrate these results empirically. We simulate 100 samples generated using 50 firms, 50 grantees, 100 districts, and 10 time periods (2.5 million observations per sample). We also generate random $X_{f d t}$ from a uniform distribution between $[0,1000]$ and $\epsilon_{f g t d}$ i.i.d. normal with mean zero and standard deviation equal to 10 (i.e., a low noise to signal ratio) or 1000 (a high noise to signal ratio). We assume $I$ ( $f$ chooses to go through $k$ at time $t)$ takes the form of a uniform random draw among all possible grantees in a district every period. We assume a true $\beta$ equal to 1 (and an intercept 10). This allows us to generate $Y_{f g t d}$.

As can be seen in Appendix Table C.15, both the the full information and the aggregate regression approaches deliver an unbiased estimate of $\beta, \beta^{\text {full }} \sim \beta^{\text {agg }} \sim 1$. The disaggregate estimator $\beta^{\text {dis }}$ delivers instead the expected $\frac{\beta}{G}$, where $1 / G=1 / 50=0.02$, due to selection, and 
irrespective of the noise/signal ratio.

\section{Proof of Claim 1}

The first-order conditions of the firm maximization problem in (6) are:

$$
\left\{\begin{array}{l}
A g^{\prime} f_{C}=q \\
A g^{\prime} f_{P}=1
\end{array}\right.
$$

We can take logarithms and differentiate each equation in (A.1):

$$
\left\{\begin{array}{l}
\frac{d A}{A}+\frac{g^{\prime \prime}}{g^{\prime}}\left(f_{C} d C+f_{P} d P\right)+\frac{f_{C P}}{f_{C}} d P+\frac{f_{C C}}{f_{C}} d C=0 \\
\frac{d A}{A}+\frac{g^{\prime \prime}}{g^{\prime}}\left(f_{C} d C+f_{P} d P\right)+\frac{f_{P P}}{f_{P}} d P+\frac{f_{P C}}{f_{P}} d C=0
\end{array}\right.
$$

Now we can exploit the homogeneity of degree of one function $f$, which implies that the marginal products $f_{C}$ and $f_{P}$ are homogeneous of degree zero. We can apply Euler's Theorem to the first derivatives $f_{C}$ and $f_{P}$ :

$$
\begin{aligned}
& C f_{C C}+P f_{C P}=0 \\
& C f_{P C}+P f_{P P}=0
\end{aligned}
$$

Therefore, the following relationships between the second-order derivatives of $f$ hold:

$$
\left\{\begin{array}{l}
f_{C C}=-\frac{P}{C} f_{C P} \\
f_{P P}=-\frac{C}{P} f_{P C}
\end{array}\right.
$$

We can substitute the expressions for $f_{C C}$ and $f_{P P}$ from (A.3) into (A.2), collect terms, and manipulate the equations to obtain the following:

$$
\left\{\begin{array}{l}
\frac{d A}{A} \frac{1}{P}+\frac{d C}{C}\left[\frac{g^{\prime \prime}}{g^{\prime}} f_{C} \frac{C}{P}-\frac{f_{C P}}{f_{C}}\right]+\frac{d P}{P}\left[\frac{g^{\prime \prime}}{g^{\prime}} f_{P}+\frac{f_{C P}}{f_{C}}\right]=0 \\
\frac{d A}{A} \frac{1}{C}+\frac{d C}{C}\left[\frac{g^{\prime \prime}}{g^{\prime}} f_{C}+\frac{f_{P C}}{f_{P}}\right]+\frac{d P}{P}\left[\frac{g^{\prime \prime}}{g^{\prime}} f_{P} \frac{P}{C}-\frac{f_{P C}}{f_{P}}\right]=0
\end{array}\right.
$$

This system of equations can then be rewritten as:

$$
\left\{\begin{array}{l}
\frac{d A}{A} \alpha+\frac{d C}{C} \beta+\frac{d P}{P} \gamma=0 \\
\frac{d A}{A} \alpha^{\prime}+\frac{d C}{C} \beta^{\prime}+\frac{d P}{P} \gamma^{\prime}=0
\end{array}\right.
$$

where $\alpha=1 / P, \alpha^{\prime}=1 / C, \beta=\frac{g^{\prime \prime}}{g^{\prime}} f_{C} \frac{C}{P}-\frac{f_{C P}}{f_{C}}, \beta^{\prime}=\frac{g^{\prime \prime}}{g^{\prime}} f_{C}+\frac{f_{P C}}{f_{P}}, \gamma=\frac{g^{\prime \prime}}{g^{\prime}} f_{P}+\frac{f_{C P}}{f_{C}}, \gamma^{\prime}=\frac{g^{\prime \prime}}{g^{\prime}} f_{P} \frac{P}{C}-\frac{f_{P C}}{f_{P}}$. 
It is easy to show that $\frac{d C}{C} / \frac{d A}{A}=\frac{d P}{P} / \frac{d A}{A}$ if and only if $\alpha^{\prime} \beta-\alpha \beta^{\prime}=\alpha \gamma^{\prime}-\alpha^{\prime} \gamma$. To complete the proof, it is easy to verify that this condition is satisfied in our system, as the following equality holds:

$$
\begin{aligned}
& \frac{1}{C}\left[\frac{g^{\prime \prime}}{g^{\prime}} f_{C} \frac{C}{P}-\frac{f_{C P}}{f_{C}}\right]-\frac{1}{P}\left[\frac{g^{\prime \prime}}{g^{\prime}} f_{C}+\frac{f_{P C}}{f_{P}}\right]= \\
& \frac{1}{P}\left[\frac{g^{\prime \prime}}{g^{\prime}} f_{P} \frac{P}{C}-\frac{f_{P C}}{f_{P}}\right]-\frac{1}{C}\left[\frac{g^{\prime \prime}}{g^{\prime}} f_{P}+\frac{f_{C P}}{f_{C}}\right]
\end{aligned}
$$

\section{C.1 Committee assignment as an asymmetric shock}

In this section we modify the exercise in section $\mathrm{V}$ to allow for an asymmetric shock caused by committee assignment. More specifically we introduce the possibility that committee assignment increases productivity of PAC expenditures more, or less, than CRS contributions. The policy production function is modified as follows:

$$
\tau=A^{\gamma} P^{\sigma}+A C^{\sigma}
$$

where $\gamma>0$ and $\sigma<1$. This functional form is a simplified version of the commonly assumed CES function in the literature on skill-biased technical change (Acemoglu, 2002). ${ }^{1}$ Notice how $\gamma$ describes the bias of the committee assignment productivity shock. If $\gamma>1$ then the committee assignment shock is P-biased (it increases productivity of $P$ more than it increases the productivity of $C$ ). If $\gamma<1$ then the reverse is true. If $\gamma=1$ then this collapses to a special case of section $\mathrm{V}$.

We can solve the firm's first order conditions to find the following elasticities of $P$ and $C$ to committee assignment shock $A$ :

$$
\begin{aligned}
& \frac{d \log C}{d \log A}=\frac{1}{1-\sigma} \\
& \frac{d \log P}{d \log A}=\frac{\gamma}{1-\sigma}
\end{aligned}
$$

Therefore in this simple case:

$$
\frac{d \log P}{d \log A}=\gamma \frac{d \log C}{d \log A}
$$

Under the same assumption that non-political charitable contributions are unresponsive to $A$, we find the share of CSR contributions that is political:

$$
\frac{C}{C+\widetilde{C}}=\gamma * 16.1 \%
$$

\footnotetext{
${ }^{1}$ In particular this is $\tau=\left(A P^{\sigma}+A^{\gamma} C^{\sigma}\right)^{\frac{\alpha}{\sigma}}$ where $\alpha=\sigma$. We can solve the more general case, but because these parameters are hard to estimate, we would have to make a number of other assumptions to make progress.
} 
Intuitively, when $\gamma$ is larger we expect the elasticity of PAC to committee assignment to be larger than the elasticity of CSR, so we need to scale up the ratio of the two elasticities to obtain the ratio of political CSR to total CSR. For example, when $\gamma=2$, i.e., committee assignment increases the productivity of PAC by twice as much as the productivity of CRS, the inferred share of political CSR is $32.2 \%$. 


\section{C.2 Additional Tables}

In this section we report various robustness checks listed in the main text. 
Table C.1: CSR Contributions and Issues Covered - Dummy Variable as Outcome

Depend. Variable: Sign(CSR Contributions from $f$ to Congr. District $d$ )

Log Issues of Interest to Found. $f$

0.009

(0.001)

0.009

Covered by Representative in $d$

$$
\text { (0.001) }
$$

Issues of Interest to Found. $f$

Covered by Representative in $d$

$$
\begin{gathered}
0.004 \\
(0.001)
\end{gathered}
$$

$(0.002)$

Any Issue of Interest to Found. $f$

0.007

0.007

Covered by Representative in $d$

(0.001)

0.004

(0.001)

\begin{tabular}{lcccccc}
\hline Fixed Effects & & & & & & \\
Found. $f \times$ State, Congress & $\mathrm{x}$ & $\mathrm{x}$ & $\mathrm{x}$ & & & \\
Found. $f \times$ Cong Dist $d$, Congress & & & & $\mathrm{x}$ & $\mathrm{x}$ & $\mathrm{x}$ \\
\hline $\mathrm{N}$ & 626,489 & 626,489 & 626,489 & 618,310 & 618,310 & 618,310 \\
$R^{2}$ & 0.299 & 0.299 & 0.299 & 0.551 & 0.551 & 0.551 \\
\hline
\end{tabular}

Notes: The Issues of Interest variables capture whether issues of interest to foundation/firm $f$ are covered by the representative in district $d$ through her committee assignment in Congress $t$. See the text for further details on the definition and variable construction. Columns (1) and (4) employ $\log (1+$ IssuesCovered) as the main explanatory variable, columns (2) and (5) employ the number of issues covered, and columns (3) and (6) use a dummy variable denoting at least 1 issue covered. The dependent variable is an indicator variable denoting non-zero CSR contributions. Standard errors are clustered at the foundation-state level. 
Table C.2: CSR and PAC Contributions, and Close Elections

\begin{tabular}{lcccc}
\hline Dep. Variable: Log Contributions from Foundation $f$ to Cong Dist $d$ \\
& $\begin{array}{c}\text { Charity } \\
(1)\end{array}$ & $\begin{array}{c}\text { PAC } \\
(2)\end{array}$ & $\begin{array}{c}\text { Charity } \\
(3)\end{array}$ & $\begin{array}{c}\text { PAC } \\
(4)\end{array}$ \\
\hline & & & & \\
& & & 0.0826 & 0.1259 \\
Margin $<5 \% * \log$ Issues & -0.0680 & 0.1123 & & \\
& $(0.0164)$ & $(0.0160)$ & & \\
Margin $<5 \%$ & 0.0946 & 0.7175 & 0.0898 & 0.5512 \\
& $(0.0155)$ & $(0.0207)$ & $(0.0166)$ & $(0.0196)$ \\
Log Issues of Interest to Found. $f$ & & & & \\
Covered by Representative in $d$ & $\mathrm{x}$ & $\mathrm{x}$ & $\mathrm{x}$ & $\mathrm{x}$ \\
\hline Fixed effects & $\mathrm{x}$ & $\mathrm{x}$ & & \\
Found. $f \times$ Cong Dist $d$ & & & $\mathrm{x}$ & $\mathrm{x}$ \\
Congress $t$ & 576,978 & 576,978 & 576,978 & 576,978 \\
Cong Dist $d \times$ Congress $t$ & 0.5803 & 0.5554 & 0.5926 & 0.5964 \\
\hline $\begin{array}{l}\text { Observations } \\
\text { R-squared }\end{array}$ &
\end{tabular}

Notes: The sample includes all district-Congress observations for the years 1996-2016. Issues of Interest is the number of issues of interest to foundation/firm $f$ that are covered by the representative in district $d$ through her committee assignment in Congress $t$. We use $\ln (1+$ IssuesCovered $)$ in all specifications. Margin is the winning vote margin in district $d$ for Congress $t$. Columns (1) and (3) use CSR contributions as the outcome while columns (2) and (4) use PAC contributions. For both measures of contributions, we employ the functional form $\ln (1+x)$ to construct the variables used in the analysis. See text for further details. Standard errors are clustered at the foundation-state level. 


\section{Table C.3: Robustness: Non-Linear Terms}

Depend. Variable: Log Contributions from $f$ to Congr. District $d$

CSR PAC CSR PAC

Log Issues of Interest to Found. $f$

$0.178 \quad 1.777$

0.161

0.971

Covered by Representative in $d$

$(0.037)$

$(0.049)$

$(0.036)$

$(0.041)$

$(\log \text { Issues })^{2}$

$\begin{array}{lll}-0.094 & -0.677 & -0.075\end{array}$

$-0.429$

(0.034)

(0.042)

(0.034)

(0.036)

\section{Fixed Effects}

Found. $f \times$ State, Congress

$\mathrm{X}$

$\mathrm{X}$

Found. $f \times$ Cong Dist $d$, Congress

\begin{tabular}{lcccc}
\hline $\mathrm{N}$ & 626,489 & 626,489 & 618,310 & 618,310 \\
$R^{2}$ & 0.323 & 0.322 & 0.592 & 0.597 \\
\hline
\end{tabular}

Notes: Issues of Interest is the number of issues of interest to foundation/firm $f$ that are covered by the representative in district $d$ through her committee assignment in Congress t. Columns (1) and (3) use CSR contributions as the outcome while columns (2) and (4) use PAC contributions. For both measures of contributions, we employ the functional form $\ln (1+x)$ to construct the variables used in the analysis. Standard errors are clustered at the foundation-state level. 
Table C.4: Robustness: Winsorized Contributions (Top 1\%)

\begin{tabular}{lcccc}
\hline Depend. Variable: Winsorized Contributions from $f$ to Congr. District $d$ \\
& $(1)$ & $(2)$ & $(3)$ & $(4)$ \\
& CSR & PAC & CSR & PAC \\
\hline & & & & \\
Log Issues of Interest to Found. $f$ & 877.997 & 520.809 & 807.752 & 244.287 \\
Covered by Representative in $d$ & $(239.758)$ & $(14.090)$ & $(210.443)$ & $(11.026)$ \\
& & & & \\
\hline & & & & \\
Fixed Effects & $\mathrm{x}$ & $\mathrm{x}$ & & \\
Found. $f \times$ State & & & $\mathrm{x}$ & $\mathrm{x}$ \\
Found. $f \times$ Cong Dist $d$ & $\mathrm{x}$ & $\mathrm{x}$ & & \\
State $\times$ Congress & & & $\mathrm{x}$ & $\mathrm{x}$ \\
Cong Dist $d \times$ Congress & 626,489 & 626,489 & 618,310 & 618,310 \\
\hline $\mathrm{N}$ & 0.266 & 0.315 & 0.644 & 0.609 \\
\hline$R^{2}$
\end{tabular}

Notes: Notes: Issues of Interest is the number of issues of interest to foundation/firm $f$ that are covered by the representative in district $d$ through her committee assignment in Congress $t$. We use $\ln (1+$ IssuesCovered) in all specifications. Columns (1) and (3) use CSR contributions as the outcome while columns (2) and (4) use PAC contributions. For both measures of contributions, we employ the functional form $\ln (1+x)$ to construct the variables used in the analysis, winsorizing the highest $1 \%$ of donations. Standard errors are clustered at the foundation-state level. 
Table C.5: PAC Contributions and Issues Covered - Time-Invariant Issues

\begin{tabular}{|c|c|c|c|c|c|c|c|c|c|c|c|c|}
\hline Depend. Variable: Log PAC Contri & $\begin{array}{l}\text { butions fre } \\
\text { (1) }\end{array}$ & $\begin{array}{l}\text { om } f \text { to } \mathrm{C} \\
(2)\end{array}$ & $\begin{array}{l}\text { ongr. Dis } \\
(3)\end{array}$ & $\begin{array}{r}\text { trict } d \\
(4)\end{array}$ & (5) & (6) & (7) & (8) & (9) & (10) & (11) & $(12)$ \\
\hline $\begin{array}{l}\text { Log Issues of Interest to Found. } f \\
\text { Covered by Representative in } d\end{array}$ & $\begin{array}{l}1.120 \\
(0.024)\end{array}$ & & & $\begin{array}{l}1.109 \\
(0.025)\end{array}$ & & & $\begin{array}{c}0.964 \\
(0.026)\end{array}$ & & & $\begin{array}{l}0.810 \\
(0.025)\end{array}$ & & \\
\hline $\begin{array}{l}\text { Issues of Interest to Found. } f \\
\text { Covered by Representative in } d\end{array}$ & & $\begin{array}{l}0.597 \\
(0.015)\end{array}$ & & & $\begin{array}{c}0.592 \\
(0.015)\end{array}$ & & & $\begin{array}{c}0.508 \\
(0.016)\end{array}$ & & & $\begin{array}{c}0.423 \\
(0.015)\end{array}$ & \\
\hline $\begin{array}{l}\text { Any Issue of Interest to Found. } f \\
\text { Covered by Representative in } d\end{array}$ & & & $\begin{array}{l}0.910 \\
(0.019)\end{array}$ & & & $\begin{array}{c}0.901 \\
(0.019)\end{array}$ & & & $\begin{array}{c}0.780 \\
(0.020)\end{array}$ & & & $\begin{array}{c}0.640 \\
(0.020)\end{array}$ \\
\hline \multicolumn{13}{|l|}{ Fixed Effects } \\
\hline Congress & $\mathrm{x}$ & $\mathrm{x}$ & $\mathrm{x}$ & & & & $\mathrm{x}$ & $\mathrm{x}$ & $\mathrm{x}$ & & & \\
\hline Found. $f \times$ State & $\mathrm{x}$ & $\mathrm{x}$ & $\mathrm{x}$ & $\mathrm{x}$ & $\mathrm{x}$ & $\mathrm{x}$ & & & & & & \\
\hline Congress $\times$ State & & & & $\mathrm{x}$ & $\mathrm{x}$ & $\mathrm{x}$ & & & & & & \\
\hline Found. $f \times$ Cong Dist $d$ & & & & & & & $\mathrm{x}$ & $\mathrm{x}$ & $\mathrm{x}$ & $\mathrm{x}$ & $\mathrm{x}$ & $\mathrm{x}$ \\
\hline Congress $\times$ Cong Dist $d$ & & & & & & & & & & $\mathrm{x}$ & $\mathrm{x}$ & $\mathrm{x}$ \\
\hline 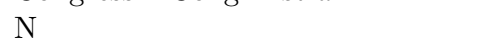 & 673,593 & 673,593 & 673,593 & 673,593 & 673,593 & 673,593 & 665,373 & 665,373 & 665,373 & 665,373 & 665,373 & 665,373 \\
\hline$R^{2}$ & 0.320 & 0.318 & 0.319 & 0.324 & 0.322 & 0.323 & 0.554 & 0.554 & 0.554 & 0.593 & 0.592 & 0.592 \\
\hline
\end{tabular}


Table C.6: CSR Contributions and Issues Covered - Time-Invariant Issues

\begin{tabular}{|c|c|c|c|c|c|c|c|c|c|c|c|c|}
\hline Depend. Variable: Log CSR Contri & $\begin{array}{l}\text { butions fre } \\
\text { (1) }\end{array}$ & $\begin{array}{l}\text { om } f \text { to } \mathrm{C} \\
(2)\end{array}$ & $\begin{array}{l}\text { ongr. Dis } \\
(3)\end{array}$ & $(4)$ & (5) & (6) & (7) & (8) & (9) & (10) & (11) & (12) \\
\hline $\begin{array}{l}\text { Log Issues of Interest to Found. } f \\
\text { Covered by Representative in } d\end{array}$ & $\begin{array}{l}0.056 \\
(0.017)\end{array}$ & & & $\begin{array}{c}0.055 \\
(0.017)\end{array}$ & & & $\begin{array}{c}0.035 \\
(0.017)\end{array}$ & & & $\begin{array}{c}0.031 \\
(0.018)\end{array}$ & & \\
\hline $\begin{array}{l}\text { Issues of Interest to Found. } f \\
\text { Covered by Representative in } d\end{array}$ & & $\begin{array}{l}0.029 \\
(0.010)\end{array}$ & & & $\begin{array}{c}0.028 \\
(0.010)\end{array}$ & & & $\begin{array}{c}0.022 \\
(0.009)\end{array}$ & & & $\begin{array}{c}0.018 \\
(0.010)\end{array}$ & \\
\hline $\begin{array}{l}\text { Any Issue of Interest to Found. } f \\
\text { Covered by Representative in } d\end{array}$ & & & $\begin{array}{l}0.047 \\
(0.014)\end{array}$ & & & $\begin{array}{c}0.046 \\
(0.014)\end{array}$ & & & $\begin{array}{c}0.025 \\
(0.014)\end{array}$ & & & $\begin{array}{c}0.023 \\
(0.015)\end{array}$ \\
\hline \multicolumn{13}{|l|}{ Fixed Effects } \\
\hline Congress & $\mathrm{x}$ & $\mathrm{x}$ & $\mathrm{x}$ & & & & $\mathrm{x}$ & $\mathrm{x}$ & $\mathrm{x}$ & & & \\
\hline Found. $f \times$ State & $\mathrm{x}$ & $\mathrm{x}$ & $\mathrm{x}$ & $\mathrm{x}$ & $\mathrm{x}$ & $\mathrm{x}$ & & & & & & \\
\hline Congress $\times$ State & & & & $\mathrm{x}$ & $\mathrm{x}$ & $\mathrm{x}$ & & & & & & \\
\hline Found. $f \times$ Cong Dist $d$ & & & & & & & $\mathrm{x}$ & $\mathrm{x}$ & $\mathrm{x}$ & $\mathrm{x}$ & $\mathrm{x}$ & $\mathrm{x}$ \\
\hline Congress $\times$ Cong Dist $d$ & & & & & & & & & & $\mathrm{x}$ & $\mathrm{x}$ & $\mathrm{x}$ \\
\hline $\mathrm{N}$ & 673,593 & 673,593 & 673,593 & 673,593 & 673,593 & 673,593 & 665,373 & 665,373 & 665,373 & 665,373 & 665,373 & 665,373 \\
\hline$R^{2}$ & 0.320 & 0.320 & 0.320 & 0.321 & 0.321 & 0.321 & 0.574 & 0.574 & 0.574 & 0.586 & 0.586 & 0.586 \\
\hline
\end{tabular}


Table C.7: Robustness: Committee Chairs and Ranking Minority Members Only

\begin{tabular}{lcccc}
\hline Depend. Variable: Log Contributions from & $f$ & to Congr. District $d$ & \\
& $(1)$ & $(2)$ & $(3)$ & $(4)$ \\
& CSR & PAC & CSR & PAC \\
\hline & & & & \\
Log Issues of Interest to Found. $f$ & 0.103 & 1.649 & 0.110 & 0.707 \\
Covered by Representative in $d$ & $(0.045)$ & $(0.057)$ & $(0.045)$ & $(0.053)$ \\
& & & & \\
\hline Fixed Effects & & & & \\
Found. $f \times$ State & $\mathrm{x}$ & $\mathrm{x}$ & & \\
Found. $f \times$ Cong Dist $d$ & $\mathrm{x}$ & $\mathrm{x}$ & & $\mathrm{x}$ \\
State $\times$ Congress & & & $\mathrm{x}$ & $\mathrm{x}$ \\
Cong Dist $d \times$ Congress & 626,489 & 626,489 & 618,310 & 618,310 \\
\hline $\mathrm{N}$ & 0.323 & 0.310 & 0.591 & 0.595 \\
$R^{2}$ & & & & \\
\hline
\end{tabular}

Notes: Issues of Interest is the number of issues of interest to foundation/firm $f$ that are covered by the representative in district $d$ through her committee assignments in Congress $t$ in which she serves as committee chair or ranking minority member. We use $\ln (1+$ IssuesCovered $)$ in all specifications. Columns (1) and (3) use CSR contributions as the outcome while columns (2) and (4) use PAC contributions. For both measures of contributions, we employ the functional form $\ln (1+x)$ to construct the variables used in the analysis. Standard errors are clustered at the foundationstate level. 
Table C.8: Robustness: Past Contributions and Future Issues Covered

\begin{tabular}{|c|c|c|c|c|c|c|c|c|}
\hline \multicolumn{9}{|c|}{ Dependent Variable: Log Issues of Interest to Found. $f$ in Congress $t$} \\
\hline $\ln C S R_{t-1}$ & $\begin{array}{c}0.0006 \\
(0.0002)\end{array}$ & $\begin{array}{c}0.0002 \\
(0.0002)\end{array}$ & $\begin{array}{l}-0.0000 \\
(0.0002)\end{array}$ & $\begin{array}{l}-0.0004 \\
(0.0003)\end{array}$ & & & & \\
\hline $\ln C S R_{t-2}$ & & $\begin{array}{c}0.0001 \\
(0.0002)\end{array}$ & $\begin{array}{l}-0.0003 \\
(0.0002)\end{array}$ & $\begin{array}{l}-0.0006 \\
(0.0003)\end{array}$ & & & & \\
\hline $\ln C S R_{t-3}$ & & & $\begin{array}{l}-0.0001 \\
(0.0002)\end{array}$ & $\begin{array}{l}-0.0003 \\
(0.0003)\end{array}$ & & & & \\
\hline $\ln C S R_{t-4}$ & & & & $\begin{array}{l}-0.0005 \\
(0.0003)\end{array}$ & & & & \\
\hline $\ln P A C_{t-1}$ & & & & & $\begin{array}{c}0.0022 \\
(0.0002)\end{array}$ & $\begin{array}{c}0.0018 \\
(0.0003)\end{array}$ & $\begin{array}{c}0.0008 \\
(0.0003)\end{array}$ & $\begin{array}{l}-0.0005 \\
(0.0004)\end{array}$ \\
\hline $\ln P A C_{t-2}$ & & & & & & $\begin{array}{l}-0.0009 \\
(0.0003)\end{array}$ & $\begin{array}{c}-0.0014 \\
(0.0003)\end{array}$ & $\begin{array}{l}-0.0022 \\
(0.0004)\end{array}$ \\
\hline $\ln P A C_{t-3}$ & & & & & & & $\begin{array}{l}-0.0016 \\
(0.0003)\end{array}$ & $\begin{array}{l}-0.0017 \\
(0.0004)\end{array}$ \\
\hline $\ln P A C_{t-4}$ & & & & & & & & $\begin{array}{l}-0.0013 \\
(0.0004)\end{array}$ \\
\hline Observations & 504,586 & 402,635 & 307,352 & 224,076 & 504,586 & 402,635 & 307,352 & 224,076 \\
\hline$R^{2}$ & 0.5372 & 0.5666 & 0.5893 & 0.6289 & 0.5374 & 0.5667 & 0.5895 & 0.6291 \\
\hline
\end{tabular}

Notes: All regressions include Foundation $\times$ Congressional District fixed effects. Issues of Interest is the number of issues of interest to foundation/firm $f$ that are covered by the representative in district $d$ through her committee assignments in Congress $t$ in which she serves as committee chair or ranking minority member. We use $\ln (1+$ IssuesCovered) as the dependent variable in all specifications. $\ln C S R_{t-1}$ is $\log (1+C S R$ Contributions $)$ from foundation/firm $f$ to charities in district $d$ during Congress $t-1$. The other independent variables are similarly defined. Standard errors are clustered at the foundation-state level. 
Table C.9: CSR to Connected Charities - Robustness 1

\begin{tabular}{|c|c|c|c|c|c|c|c|c|c|c|}
\hline \multicolumn{11}{|c|}{ Dependent variable: $\log$ (total contributions received from corporate foundations) } \\
\hline & (1) & (2) & (3) & (4) & (5) & $(6)$ & $(7)$ & (8) & $(9)$ & (10) \\
\hline Number of connections to Congress & & $\begin{array}{c}3.878 \\
(0.044)\end{array}$ & & $\begin{array}{c}3.525 \\
(0.043)\end{array}$ & & $\begin{array}{c}3.474 \\
(0.044)\end{array}$ & & $\begin{array}{c}3.423 \\
(0.044)\end{array}$ & & $\begin{array}{c}3.150 \\
(0.043)\end{array}$ \\
\hline Log Income & & & $\begin{array}{l}54.705 \\
(1.058)\end{array}$ & $\begin{array}{l}54.704 \\
(1.058)\end{array}$ & $\begin{array}{c}53.618 \\
(1.069)\end{array}$ & $\begin{array}{l}53.620 \\
(1.069)\end{array}$ & $\begin{array}{l}35.957 \\
(1.084)\end{array}$ & $\begin{array}{l}35.946 \\
(1.085)\end{array}$ & $\begin{array}{l}25.045 \\
(1.084)\end{array}$ & $\begin{array}{l}25.023 \\
(1.084)\end{array}$ \\
\hline Log Assets & & & $\begin{array}{l}12.510 \\
(1.067)\end{array}$ & $\begin{array}{l}12.619 \\
(1.067)\end{array}$ & $\begin{array}{l}12.088 \\
(1.081)\end{array}$ & $\begin{array}{l}12.192 \\
(1.081)\end{array}$ & $\begin{array}{l}32.181 \\
(1.106)\end{array}$ & $\begin{array}{l}32.293 \\
(1.106)\end{array}$ & $\begin{array}{l}40.936 \\
(1.108)\end{array}$ & $\begin{array}{l}41.041 \\
(1.109)\end{array}$ \\
\hline City, State & & & & & $\mathrm{x}$ & $\mathrm{x}$ & $\mathrm{x}$ & $\mathrm{x}$ & $\mathrm{x}$ & $\mathrm{x}$ \\
\hline Coarse non-profit sector (A-Z) & & & & & & & $\mathrm{x}$ & $\mathrm{x}$ & & \\
\hline Detailed non-profit sector (NTEECC) & & & & & & & & & $\mathrm{x}$ & $\mathrm{x}$ \\
\hline Observations & $2,179,096$ & $2,179,096$ & $2,179,096$ & $2,179,096$ & $2,177,907$ & $2,177,907$ & $2,177,907$ & $2,177,907$ & $2,177,907$ & $2,177,907$ \\
\hline R-squared & 0.017 & 0.016 & 0.052 & 0.052 & 0.068 & 0.067 & 0.075 & 0.074 & 0.107 & 0.107 \\
\hline
\end{tabular}


Table C.10: CSR to Connected Charities - Robustness 2

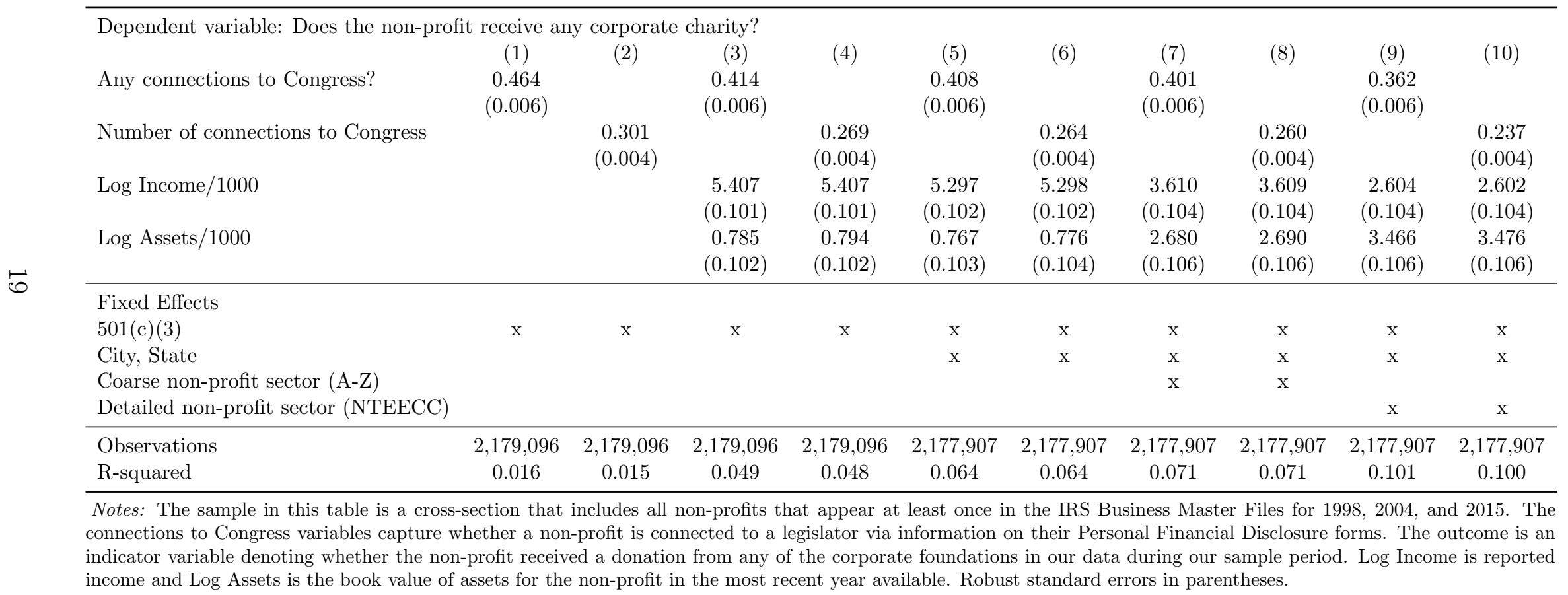


Table C.11: CSR Contributions to Relevant Charities

\begin{tabular}{|c|c|c|c|c|c|c|c|c|c|c|c|c|c|c|}
\hline \multicolumn{15}{|c|}{ Dependent Variable: $\log (1+$ Charitable Contributions $)$} \\
\hline & (1) & (2) & (3) & $(4)$ & (5) & $(6)$ & (7) & $(8)$ & (9) & (10) & (11) & $(12)$ & (13) & (14) \\
\hline $\begin{array}{l}\text { Relevance/1000 } \\
\text { (Issue-Congressmen pairs) }\end{array}$ & $\begin{array}{c}8.277 \\
(0.851)\end{array}$ & & & & $\begin{array}{c}5.042 \\
(0.794)\end{array}$ & & & & $\begin{array}{c}1.547 \\
(0.545)\end{array}$ & & & & & \\
\hline $\begin{array}{l}\text { Relevance/1000 } \\
\text { (Congressmen) }\end{array}$ & & $\begin{array}{l}32.760 \\
(2.354)\end{array}$ & & & & $\begin{array}{l}15.250 \\
(1.965)\end{array}$ & & & & $\begin{array}{c}2.177 \\
(1.416)\end{array}$ & & & & \\
\hline $\begin{array}{l}\text { Relevance/1000 } \\
\text { (Issues) }\end{array}$ & & & $\begin{array}{l}8.208 \\
(0.845)\end{array}$ & & & & $\begin{array}{c}4.951 \\
(0.785)\end{array}$ & & & & $\begin{array}{c}1.487 \\
(0.543)\end{array}$ & & & \\
\hline Any relevance?/1000 & & & & $\begin{array}{l}23.038 \\
(1.769)\end{array}$ & & & & $\begin{array}{c}7.446 \\
(1.526)\end{array}$ & & & & $\begin{array}{c}2.292 \\
(1.313)\end{array}$ & $\begin{array}{c}2.867 \\
(1.379)\end{array}$ & $\begin{array}{c}0.237 \\
(0.145)\end{array}$ \\
\hline \multicolumn{15}{|l|}{ Fixed Effects: } \\
\hline Found. $f$ & $\mathrm{x}$ & $\mathrm{x}$ & $\mathrm{x}$ & $\mathrm{x}$ & $\mathrm{x}$ & $\mathrm{x}$ & $\mathrm{x}$ & $\mathrm{x}$ & & & & & & \\
\hline Charity $c$ & & & & & $\mathrm{x}$ & $\mathrm{x}$ & $\mathrm{x}$ & $\mathrm{x}$ & & & & & & \\
\hline Year $t$ & $\mathrm{x}$ & $\mathrm{x}$ & $\mathrm{x}$ & $\mathrm{x}$ & $\mathrm{x}$ & $\mathrm{x}$ & $\mathrm{x}$ & $\mathrm{x}$ & $\mathrm{x}$ & $\mathrm{x}$ & $\mathrm{x}$ & $\mathrm{x}$ & $\mathrm{x}$ & $\mathrm{x}$ \\
\hline Found. $f \times$ Charity $c$ & & & & & & & & & $\mathrm{x}$ & $\mathrm{x}$ & $\mathrm{x}$ & $\mathrm{x}$ & $\mathrm{x}$ & $\mathrm{x}$ \\
\hline Charity $c \times$ Congress & & & & & & & & & & & & & $\mathrm{x}$ & $\mathrm{x}$ \\
\hline Found. $f \times$ Congress & & & & & & & & & & & & & & $\mathrm{x}$ \\
\hline Observations & $4,054,160$ & $4,054,160$ & $4,054,160$ & $4,054,160$ & $4,054,160$ & $4,054,160$ & $4,054,160$ & $4,054,160$ & $4,054,160$ & $4,054,160$ & $4,054,160$ & $4,054,160$ & $4,054,160$ & $4,054,160$ \\
\hline R-squared & 0.013 & 0.014 & 0.013 & 0.013 & 0.061 & 0.061 & 0.061 & 0.061 & 0.463 & 0.463 & 0.463 & 0.463 & 0.468 & 0.451 \\
\hline
\end{tabular}


Table C.12: Pair-Level Analysis

Dependent variable: Does the non-profit receive any corporate charity?

Log Issues of Interest to Found. $f$

Covered by Repres. linked to charity $g$

0.0690

$(0.0056)$

0.0037

$(0.0012)$

Log Issues of Interest to Found. $f$

Covered by Representative in $d$

\section{Fixed Effects}

Foundation $f$

Grantee $g$

Congress

Found $f \times$ Grantee $g$

Found $f \times$ Congress

Grantee $g \times$ Congress

0.0107

(0.0051)

0.0129

(0.0058)

$0.0016 \quad 0.0021$

(0.0006)

0.0004

$(0.0006)$
(0.0058) (0.0070)

$(0.0005)$

-

$\begin{array}{ll}\mathrm{x} & \\ \mathrm{x} & \mathrm{x} \\ \mathrm{x} & \mathrm{x}\end{array}$

$\mathrm{x}$
$\mathrm{x}$

$\begin{array}{lll}\mathrm{x} & \mathrm{x} & \\ \mathrm{x} & \mathrm{x} & \mathrm{x} \\ & \mathrm{x} & \mathrm{x}\end{array}$

\begin{tabular}{lccccc}
\hline Observations & $73,107,477$ & $71,195,937$ & $71,195,937$ & $71,195,937$ & $73,107,477$ \\
R-squared & 0.0277 & 0.4780 & 0.4829 & 0.4854 & 0.0352 \\
\hline
\end{tabular}

Notes: The sample includes all foundation-nonprofit-Congress combinations for non-profits that receive at least one donation from a foundation/firm in our dataset during our sample period. The dependent variable is an indicator variable denoting whether non-profit $g$ received a donation from foundation/firm $f$ in Congress $t$. The Issues of Interest variables capture whether issues of interest to foundation/firm $f$ are covered by a representative through her committee assignment in Congress $t$. The first measure is based on personal ties listed on legislators' Personal Financial Disclosures. The second is based on whether the non-profit is located in the legislator's district. In both cases we use $\ln (1+$ IssuesCovered $)$. See text for further details on the sample, estimation methodology, and variable construction. Standard errors are clustered at the foundation $f \times$ congressional district level. 


\section{Table C.13: Pair-Level Analysis - Congressional District Clustering}

Dependent variable: Does the non-profit receive any corporate charity?

Log Issues of Interest to Found. $f$

Covered by Repres. linked to charity $g$

Log Issues of Interest to Found. $f$

\section{Fixed Effects}

Foundation $f$

Grantee $g$

Congress

Found $f \times$ Grantee $g$

Found $f \times$ Congress

Grantee $g \times$ Congress

\section{$\mathrm{X}$}

$\mathrm{X}$

$\mathrm{X}$
$\mathrm{X}$

$\mathrm{X}$ $\mathrm{x}$

$\mathrm{x} \quad \mathrm{x} \quad \mathrm{x}$

\begin{tabular}{lccccc}
\hline Observations & $73,107,477$ & $71,195,937$ & $71,195,937$ & $71,195,937$ & $73,107,477$ \\
R-squared & 0.0277 & 0.4780 & 0.4829 & 0.4854 & 0.0352 \\
\hline
\end{tabular}

Notes: The sample includes all foundation-nonprofit-Congress combinations for non-profits that receive at least one donation from a foundation/firm in our dataset during our sample period. The dependent variable is an indicator variable denoting whether non-profit $g$ received a donation from foundation/firm $f$ in Congress $t$. The Issues of Interest variables capture whether issues of interest to foundation/firm $f$ are covered by a representative through her committee assignment in Congress $t$. The first measure is based on personal ties listed on legislators' Personal Financial Disclosures. The second is based on whether the non-profit is located in the legislator's district. In both cases we use $\ln (1+$ IssuesCovered $)$. See text for further details on the sample, estimation methodology, and variable construction. Standard errors are clustered at the congressional district level. 


\section{Table C.14: Pair-Level Analysis - Redistricting}

Dependent variable: Does the non-profit receive any corporate charity?

Log Issues of Interest to Found. 0.0064

0.0036

0.0043

0.0024

0.0050

Covered by Representative in $d$

$(0.0022)$

$(0.0012)$

$(0.0014)$

$(0.0013)$

\section{Fixed Effects}

Foundation $f$

Grantee $g$

Congress

Found $f \times$ Grantee $g$

Found $f \times$ Congress

Grantee $g \times$ Congress
$\mathrm{X}$

$\mathrm{X}$

$\mathrm{X}$
$\mathrm{X}$

$\mathrm{X}$
$\mathrm{X}$

$\mathrm{X}$
$\mathrm{X}$

$\mathrm{X}$

$\mathrm{X}$
$\mathrm{X}$

$\mathrm{X}$

\begin{tabular}{lccccc}
\hline Observations & $8,711,875$ & $7,989,086$ & $7,989,086$ & $7,989,086$ & $8,711,875$ \\
R-squared & 0.0380 & 0.6936 & 0.6958 & 0.6980 & 0.0444 \\
\hline
\end{tabular}

Notes: The sample includes all non-profits that experience a shift in congressional district. We include the Congresses immediately pre- and post-redistricting (i.e., Congresses 107, 108, 112 and 113). The data are at the level of foundation-nonprofit-Congress, and includes non-profits that receive at least one donation from a foundation/firm in our dataset. The dependent variable is an indicator variable denoting whether non-profit $g$ received a donation from foundation/firm $f$ in Congress $t$. The Issues of Interest variables capture whether issues of interest to foundation/firm $f$ are covered by the representative of district $d$ through her committee assignment in Congress $t$. Standard errors are clustered at the foundation $f \times$ congressional district level. 
Table C.15: Monte Carlo Simulations for Disaggregate Regression

\begin{tabular}{lccccc}
\hline Specification & $\begin{array}{c}\text { Number of } \\
\text { Simulations }\end{array}$ & Mean & Std Dev & Min & Max \\
\hline Panel A. Beta =1, high noise/signal ratio & & & & \\
$\begin{array}{l}\text { Disaggregate And Selection } \\
\text { Disaggregate }\end{array}$ & 100 & 0.9995 & 0.0073 & 0.9831 & 1.0167 \\
Aggregate & 100 & 0.0204 & 0.0025 & 0.0151 & 0.0270 \\
& 100 & 1.0179 & 0.1229 & 0.7544 & 1.3508 \\
& & & & & \\
\hline $\begin{array}{l}\text { Panel B. Beta =1, low noise/signal ratio } \\
\text { Disaggregate And Selection }\end{array}$ & 100 & 0.9999 & 0.0001 & 0.9998 & 1.0002 \\
Disaggregate & 100 & 0.0200 & 0.0000 & 0.0200 & 0.0201 \\
Aggregate & 100 & 1.0002 & 0.0012 & 0.9975 & 1.0035 \\
& & & & & \\
\hline
\end{tabular}

Notes: This table reports regression coefficients (elasticities) from models estimated with 50 firms, 50 grantees, 100 districts, and 10 time periods. The true elasticity equal to 1 . The variance of regression error to independent variable variance is equal to 1 in Panel $\mathrm{A}$ and 1/10 in Panel B. We assume uniform random selection of grantee recipient in each period. See the text for further details. 


\section{C.3 Lobbying Issues}

Table C.16: Lobbying Issues

\begin{tabular}{|c|c|c|c|}
\hline $\mathrm{ACC}$ & Accounting & $\mathrm{HOM}$ & Homeland Security \\
\hline $\mathrm{ADV}$ & Advertising & $\mathrm{HOU}$ & Housing \\
\hline AER & Aerospace & IMM & Immigration \\
\hline AGR & Agriculture & IND & Indian/Native American Affairs \\
\hline $\mathrm{ALC}$ & Alcohol \& Drug Abuse & INS & Insurance \\
\hline ANI & Animals & INT & Intelligence and Surveillance \\
\hline APP & Apparel/Clothing Industry/Textiles & LBR & Labor Issues/Antitrust/Workplace \\
\hline ART & Arts/Entertainment & LAW & Law Enforcement/Crime/Criminal Justice \\
\hline AUT & Automotive Industry & MAN & Manufacturing \\
\hline AVI & Aviation/Aircraft/Airlines & MAR & Marine/Maritime/Boating/Fisheries \\
\hline BAN & Banking & MIA & Media (Information/Publishing) \\
\hline BNK & Bankruptcy & MED & Medical/Disease Research/Clinical Labs \\
\hline BEV & Beverage Industry & MMM & Medicare/Medicaid \\
\hline BUD & Budget/Appropriations & MON & Minting/Money/Gold Standard \\
\hline $\mathrm{CHM}$ & Chemicals/Chemical Industry & NAT & Natural Resources \\
\hline CIV & Civil Rights/Civil Liberties & PHA & Pharmacy \\
\hline CAW & Clean Air \& Water (Quality) & POS & Postal \\
\hline CDT & Commodities (Big Ticket) & $\mathrm{RRR}$ & Railroads \\
\hline $\mathrm{COM}$ & Communications/Broadcasting/Radio/TV & RES & Real Estate/Land Use/Conservation \\
\hline CPI & Computer Industry & REL & Religion \\
\hline CSP & Consumer Issues/Safety/Protection & RET & Retirement \\
\hline $\mathrm{CON}$ & Constitution & ROD & Roads/Highway \\
\hline $\mathrm{CPT}$ & Copyright/Patent/Trademark & SCI & Science/Technology \\
\hline $\mathrm{DEF}$ & Defense & SMB & Small Business \\
\hline DOC & District of Columbia & $\mathrm{SPO}$ & Sports/Athletics \\
\hline DIS & Disaster Planning/Emergencies & TAR & Miscellaneous Tariff Bills \\
\hline $\mathrm{ECN}$ & Economics/Economic Development & TAX & Taxation/Internal Revenue Code \\
\hline EDU & Education & TEC & Telecommunications \\
\hline ENG & Energy/Nuclear & TOB & Tobacco \\
\hline ENV & Environmental/Superfund & TOR & Torts \\
\hline FAM & Family Issues/Abortion/Adoption & TRD & Trade (Domestic \& Foreign) \\
\hline FIR & Firearms/Guns/Ammunition & TRA & Transportation \\
\hline FIN & Financial Institutions/Investments/Securities & TOU & Travel/Tourism \\
\hline FOO & Food Industry (Safety, Labeling, etc.) & TRU & Trucking/Shipping \\
\hline FOR & Foreign Relations & URB & Urban Development/Municipalities \\
\hline FUE & Fuel/Gas/Oil & UNM & Unemployment \\
\hline GAM & Gaming/Gambling/Casino & UTI & Utilities \\
\hline GOV & Government Issues & VET & Veterans \\
\hline \multirow[t]{2}{*}{ HCR } & Health Issues & WAS & Waste (hazardous/solid/interstate/nuclear) \\
\hline & & WEL & Welfare \\
\hline
\end{tabular}

